\title{
Erectile dysfunction and exposure to ambient air pollution in a nationally representative cohort of older men
}

Lindsay A. Tallon 1,2, Justin Manjourides', Vivian C. Pun', Murray A. Mittleman³, Marianthi-Anna Kioumourtzoglou ${ }^{4}$, Brent Coull ${ }^{5}$ and Helen Suh ${ }^{6^{*}}$

\begin{abstract}
Background: Little is known about the association between air pollution and erectile dysfunction (ED), a disorder occurring in $64 \%$ of men over the age of 70 , and to date, no studies have been published. To address this significant knowledge gap, we explored the relationship between ED and air pollution in a group of older men who were part of the National Social Life, Health, and Aging Project (NSHAP), a nationally representative cohort study of older Americans.

Methods: We obtained incident ED status and participant data for 412 men (age 57-85). Fine particulate matter (PM 2.5$)$ exposures were estimated using spatio-temporal models based on participants' geocoded addresses, while nitrogen dioxide $\left(\mathrm{NO}_{2}\right)$ and ozone $\left(\mathrm{O}_{3}\right)$ concentrations were estimated using nearest measurements from the Environmental Protection Agency's Air Quality System. The association between air pollution and incident ED (newly developed in Wave 2) was examined and logistic regression models were run with adjusted models controlling for race, education, season, smoking, obesity, diabetes, depression, and median household income of census tract.

Results: We found positive, although statistically insignificant, associations between $\mathrm{PM}_{2.5}, \mathrm{NO}_{2}$, and $\mathrm{O}_{3}$ exposures and odds of incident ED for each of our examined exposure windows, including 1 to 7 year moving averages. Odds ratios (OR) for 1 and 7 year moving averages equaled 1.16 (95\% Cl: $0.87,1.55)$ and 1.16 (95\% Cl: 0.92, 1.46), respectively, for an IQR increase in $\mathrm{PM}_{2.5}$ exposures. Observed associations were robust to model specifications and were not significantly modified by any of the examined risk factors for ED.

Conclusions: We found associations between $\mathrm{PM}_{2.5}, \mathrm{NO}_{2}$, and $\mathrm{O}_{3}$ exposures and odds of developing $\mathrm{ED}$ that did not reach nominal statistical significance, although exposures to each pollutant were consistently associated with higher odds of developing ED. While more research is needed, our findings suggest a relationship between air pollutant exposure and incident cases of ED, a common condition in older men.
\end{abstract}

Keywords: Men, Vasculature, Erectile dysfunction, $\mathrm{PM}_{2.5}$

\section{Background}

Erectile dysfunction (ED), defined as the inability of a man to achieve or maintain an erection [1], is one of the most common health conditions affecting older men. Prevalence of ED is estimated to equal $20-40 \%$ in men aged 60-69 years and 64\% in men over the age of 70 [2], with 617,715 new cases of ED expected each year in the

\footnotetext{
* Correspondence: helen.suh@tufts.edu

${ }^{6}$ Department of Civil and Environmental Engineering, Tufts University, 200

College Avenue, 301 Anderson Hall, Medford, MA 02155, USA

Full list of author information is available at the end of the article
}

United States among white males between 40 and 69 years old [3]. With the aging of the population, it is estimated that globally by the year 2025 , over 320 million men will have ED [4]. ED has a considerable impact on quality of life, having been associated with a variety of underlying psychological and physiological conditions, such as depression, Type 1 and Type 2 diabetes mellitus, use of medications, and cardiovascular disease [5]. However, ED is often left untreated, with as few as $10 \%$ of men with ED receiving treatment [6]. Both treatment and prevention of ED includes lifestyle modifications like 
exercise, weight loss, smoking cessation, and treatment for comorbid conditions [5].

ED is a complex neurovascular process, influenced by hormones and involves multiple pathways within the body. ED is a predictor of occult and subclinical cardiovascular disease [7] that often occurs in 3 to 5 years after ED diagnosis [7, 8]. Given this, it is not surprising that ED has been shown to share a number of risk factors with cardiovascular disease, including restricted blood flow and vascular compromise with endothelial dysfunction at both the macro and microvascular level $[9,10]$. It is also plausible that ED shares other risk factors with cardiovascular disease, including air pollutants such as fine particulate matter $\left(\mathrm{PM}_{2.5} ;\right.$ particles with aerodynamic diameters $\leq 2.5 \mu \mathrm{m})$ [11]. $\mathrm{PM}_{2.5}$ in particular has consistently been shown to be strongly associated with cardiovascular morbidity and mortality [12, 13]. The biological pathways through which $\mathrm{PM}_{2.5}$ leads to cardiovascular damage is thought to occur primarily through inflammation and oxidative stress [14], leading to systemic vascular and endothelial cell dysfunction $[14,15]$. Whether $\mathrm{PM}_{2.5}$ 's impacts on systemic vascular dysfunction also lead to ED is unknown. To our knowledge, no studies to date have been published investigating the association between air pollution and ED. To address this significant knowledge gap, we investigated the association between air pollution and incident ED using a nationally representative cohort study of older men from the National Social Life, Health, and Aging Project (NSHAP).

\section{Methods}

\section{Study participants}

NSHAP is a longitudinal, population-based study of community-dwelling older adults, who were selected for participation based on a nationally representative probability sample of household-resident older adults aged 57-85 years, with oversampling of African-Americans, Hispanics, men, and adults aged 75-84 years. Numerous self-reported and biological measures of social, psychological, functional, and physiological health were collected for each participant in each of two data collection waves. The first wave (Wave 1) was conducted from July 2005 to March 2006, with in-home interviews, biospecimen collection, and respondent-completed questionnaires performed for 3,005 individuals (1,455 men). The same data were obtained in Wave 2 (August 2010 to May 2011) for 3,377 participants (1,538 men), including 2,261 respondents from Wave 1, 161 Wave 1 eligible, but non-interviewed respondents, and 955 spouses or cohabitating romantic partners. The overall weighted response rate (weighted for differential probabilities of selection and nonresponse) among the 2,261 individuals (1068 men) who participated in both waves was $75.5 \%$ and $76.9 \%$ for Waves 1 and 2 respectively, and interviews were completed in English or Spanish as appropriate.[16] The protocol was approved by the Institutional Review Boards of Northeastern University, the University of Chicago and NORC at the University of Chicago. All respondents provided written informed consent.

\section{ED measures}

ED status was obtained through self-report to the question asking men if "during the last 12 months has there ever been a period of several months or more when you had trouble getting or maintaining an erection?" This question was administered only to men who reported sexual activity within one year of the interview date in Wave 1 and of all men in Wave 2. Information on ED medication use and prostatectomy surgery was also collected via questionnaire. Men were counted as having ED if they answered yes to having ED or taking medications to treat ED. Incident cases were defined as men who participated in both waves and developed ED between Wave 1 and Wave 2 .

\section{Other covariates}

Measures of height and weight were taken at the time of the interview to calculate to body mass index (BMI), with a BMI of 30 or greater $\mathrm{kg} / \mathrm{m}^{2}$ defined as obese [17]. Additionally, blood spot samples were collected and blood pressure was measured for each participant (2-3 consecutive times) during the home interview. Blood pressure was estimated as the average of the repeated measurements, with hypertension defined as having average systolic and diastolic measurement of greater than $140 \mathrm{mmHg}$ and $90 \mathrm{mmHg}$, respectively [18]. C-Reactive Protein (CRP) was measured from dried blood samples, and was considered elevated if greater than $1 \mathrm{mg} / \mathrm{L}$. Participants with CRP measurements greater than $40 \mathrm{mg} / \mathrm{L}$ were not included in CRP analyses, given the likelihood of an active infection [19].

In addition, information on medical conditions, like diabetes, and measures of activity, such as exercise and ability to walk across a room, were obtained through participant self-report. Measures of emotional health were also obtained, with depression assessed using an eleven question version of the Center for Epidemiological Studies Depression scale, CESD-11 [20]. A score of 9 or greater on the CESD-11 was used to identify individuals with "moderate-to-severe" depressive symptoms [20, 21].

Finally, information on census tract characteristics including the tract median household income was obtained from the 2010 US Census and matched to participants based on their geocoded residence. A participant's place of residence was also used to determine the geographic region of the United States in which they resided (West, Midwest, Central, South, Northeast). The regional divisions are based off of the Environmental Protection Agency's (EPA's) regional planning organizations. 


\section{Air pollution exposure assessment}

Daily $\mathrm{PM}_{2.5}$ exposures were estimated on a $6 \mathrm{~km}(\mathrm{~km})$ grid covering the conterminous United States using a set of five spatio-temporal generalized additive mixed models (GAMMs) of daily $\mathrm{PM}_{2.5}$ mass levels fit separately to 19992001, 2002-2004, 2005-2007, 2008-2009, and 2010-2011 based on previous work from Yanosky et al. [22]. $\mathrm{PM}_{2.5}$ data for the models were obtained primarily from the EPA's Air Quality System (AQS) database and Interagency Monitoring of Protected Visual Environments (IMPROVE) network [23, 24]. The models included three meteorological covariates (i.e., wind speed, temperature, and total precipitation) that influence pollutant dispersion as well as several geospatial covariates such as smoothed county population density from the 2000 U.S. census, point-source $\mathrm{PM}_{2.5}$ emissions density within $7.5 \mathrm{~km}$, proportion of urban land use within $1 \mathrm{~km}$, elevation, and annual-average $\mathrm{PM}_{2.5}$ for 2002 from EPA's Community Multiscale Air Quality model. Finally, the daily $\mathrm{PM}_{2.5}$ models include traffic-related PM levels, represented as the output of a Gaussian line-source dispersion modeling approach. The line-source model uses ADMS-Roads software and associated spatially-smoothed traffic intensity and daily meteorological inputs to describe small-scale spatial gradients in primary PM concentrations near roadways. The daily $\mathrm{PM}_{2.5}$ model was validated using cross-validation techniques, as in Yanosky et al. [22], and had a cross-validation $\mathrm{R}^{2}$ of 0.76 . Cases and controls were matched by date of interview to the $\mathrm{PM}_{2.5}$ grid values closest to their residential addresses, taking into account moves between waves. One to seven year moving averages from the date of interview were calculated from the daily $\mathrm{PM}_{2.5}$ estimates. The mean distance between each grid centroid-residential address pair was $2.23 \mathrm{~km}$, with a range of $0.05-4.21 \mathrm{~km}$.

As secondary analyses, exposures to ozone $\left(\mathrm{O}_{3}\right)$ and nitrogen dioxide $\left(\mathrm{NO}_{2}\right)$ were also estimated using data from the EPA's AQS. For both $\mathrm{O}_{3}$ and $\mathrm{NO}_{2}$, participants were matched to the AQS monitor nearest to their residential address, provided that this monitor was located within $60 \mathrm{~km}$ of the participant's home. Air pollution exposures were estimated for 93\% (for $\mathrm{O}_{3}$ ) and 63\% (for $\mathrm{NO}_{2}$ ) of all male NSHAP participants. For $\mathrm{NO}_{2}, 1-7$ year moving averages from the date of interview were calculated. For $\mathrm{O}_{3}, 1-7$ year average exposures preceding the interview date were calculated based on the average warm season (April-September) concentration, since $\mathrm{O}_{3}$ is measured at most monitoring sites only during warmer months. Moving averages for each pollutant were considered valid if $\geq 75 \%$ of the daily values within each exposure window were available.

\section{Statistical analyses}

To investigate the association between chronic air pollutant exposures and incident ED, we performed logistic regression analyses, with the outcome of incident ED defined as men reporting either ED or ED medication use in Wave 2 but not Wave 1. Base models controlled for covariates including age and geographic region, while adjusted models additionally controlled for race/ethnicity (white, black, Hispanic non-black, other), education (proxy variable for socioeconomic status (SES), less than high school, completed high school or vocational school, college degree), current smoking status, obesity, diabetes, depression, season, and median household income of the census tract. Covariates were included based upon previous, known associations with either air pollution exposures or ED. Results for all models are expressed as the odds ratios (ORs) of having ED per interquartile range (IQR) increase in ambient air pollution exposure.

Due to missingness in ED, BMI, and diabetes $(39.6 \%$ missing incident ED outcome in Wave 1 and $13.6 \%$ outcome missing in Wave 2, 5.1\% missing BMI in both waves, and $0.6 \%$ missingness for diabetes in both waves), we used multiple imputation to impute missing data. We did so using the fully conditional specification (FCS) algorithm with 100 imputed datasets created given the logistic model and binary data used in the model [25]. Variables used in imputation included the outcome of incident ED, any factors relating to ED (CRP, ability to walk across a room, antiandrogens, and beta blockers) as well as all covariates included in the model. Imputation resulted in a data set containing all men who participated in both waves $(n=1068)$.

We examined effect modification of the association between $\mathrm{PM}_{2.5}$ and incident ED by including separate interactions between $\mathrm{PM}_{2.5}$ and obesity, hypertension, diabetes, CRP, exercise (as less or greater than once each week), current smoking, and depression. These potential modifiers were selected based on previous scientific findings for air pollution and cardiovascular disease. All effect modification analyses were performed for 4 year moving average $\mathrm{PM}_{2.5}$ exposures since it was the interval with the strongest observed effect estimate.

Sensitivity analyses were performed to examine the robustness of our findings to (1) alternate definitions of ED and geographic region, (2) residential moves, (3) treating ED as a reversible outcome, and (4) imputation of ED data. We examined the robustness of our findings with regard to our definition of ED as well as how the geographic regions of the U.S. were defined. We did so repeating our primary analyses but defining ED as only those men who reported having $\operatorname{ED}(n=129)$ as opposed to also including men reporting ED medication usage and by defining region based on 4 (North, South, East, and West) as opposed to the 5 regions used in the primary analyses. We further assessed the sensitivity of our findings to residential moves by restricting the analyses to men who did not move during the study. Finally, to 
explore the relation of air pollution to ED prevalence while treating ED as a reversible outcome [26], we included all cases of ED $(n=746)$ in generalized mixed models with random intercepts, rather than just incident cases of ED. As before, models included adjustments for age, race/ethnicity, education, year, season, current smoking, obesity, diabetes, depression, median household income, and region. Similar to our primary analyses, additional covariates were selected based on previous scientific findings to investigate effect modification. Finally, complete case analyses were undertaken to examine the potential effects of imputation.

All statistical analyses were conducted using SAS version 9.4 software (SAS Institute Inc., Cary, North Carolina). Statistical significance is reported at the two-sided 0.05 level.

\section{Results}

In Wave 2, 132 men answered yes for the first time to either having ED (129 men) or to ED medication use (10 men total, 3 men with medication usage alone), with these men defined as incident ED cases for our study period (Table 1). The number of incident ED cases was small relative to the number of men reporting ED in Wave 1, for which 331 men reported having ED and 29 reported being on ED medication. Over both waves, 280 men did not report developing ED and were the comparison group in our main analysis (Table 1). The majority of men with incident ED were non-Hispanic White (78.79\%), with the average age of 70.3 years. Compared to men without ED, those with ED were more likely to be non-Hispanic Whites, have higher education levels, and be obese. Other demographic characteristics of men with and without ED were similar. One year mean moving averages for $\mathrm{PM}_{2.5}$ during Wave 2 were $8.9 \mu \mathrm{g} / \mathrm{m}^{3}$ $( \pm 2.1)$ for men with ED and $8.6 \mu \mathrm{g} / \mathrm{m}^{3}( \pm 2.3)$ for men without ED. A comparison of men with and without data for prevalent ED (provided in Additional file 1: Table S1) showed that, depending on the wave, men differed significantly in the distribution of major risk factors for ED including age, education, diabetes status, obesity rates, depression and stress.

Table 2 presents the associations between incident ED and moving average $\mathrm{PM}_{2.5}$ exposures over 1 to 7 years prior to the interview date for both base and adjusted models for imputed data. An IQR increase in 1 year moving average $\mathrm{PM}_{2.5}$ exposure $\left(3.25 \mu \mathrm{g} / \mathrm{m}^{3}\right)$ was associated with a $1.16(95 \% \mathrm{CI}: 0.87,1.55)$ times higher odds of developing ED, with similar results for an IQR increase in the 7 year moving average exposure $(3.10 \mu \mathrm{g} /$ $\mathrm{m}^{3}$, OR $\left.=1.16(95 \% \mathrm{CI}, 0.92,1.46)\right)$. The association between $\mathrm{PM}_{2.5}$ and ED was not significantly modified by adverse health conditions, such as being obese or having elevated CRP, diabetes, hypertension, depression, or by behaviors such as current smoking or exercise (Table 3), although the estimated ORs were consistently higher for individuals without adverse health conditions.

As for $\mathrm{PM}_{2.5}$ exposures, 1-7 year moving averages of $\mathrm{O}_{3}$ and $\mathrm{NO}_{2}$ exposures were positively associated with odds of having incident ED, although associations did not reach nominal statistical significance (Table 4). ORs increased with longer moving averages, with the largest odds ratio for $\mathrm{O}_{3}$ and incident ED observed for an IQR increase in exposures averaged over 2 years $(\mathrm{OR}=1.29$, 95\% CI, 0.93, 1.79).

Analyses conducted using different definitions of ED and geographic regions as well as restricting analyses to men who did not have residential moves between waves showed qualitatively comparable results. For example, including only those men who answered yes to the ED question as men with incident ED $(n=129)$, in adjusted models we found $\mathrm{PM}_{2.5}$-associated $\mathrm{ORs}$ ranging from $1.10(95 \% \mathrm{CI}, 0.75,1.62)$ for an IQR increase in the 1 year moving average exposure to 1.12 (95\% CI, 0.82, 1.52) for an IQR increase in the 7 year moving average exposure. Analyses of all ED cases from both waves, assuming ED is a reversible outcome, showed no statistically significant association with pollutant exposures. For example, the OR associated with IQR increases in $\mathrm{PM}_{2.5} 7$ year moving average exposures was 1.06 (95\% CI, 0.86, 1.30, Additional file 1: Table S2).

Analyses restricted to complete cases (Additional File 1: Table S3), had similar results to imputed data (Table 2) but with slightly lower estimates. An IQR increase in 1 year moving average $\mathrm{PM}_{2.5}$ exposure was associated with a 1.11 (95\% CI: 0.76, 1.61) times higher odds of developing ED, while an IQR increase in 7 year moving average $\mathrm{PM}_{2.5}$ exposure was associated with a 1.14 (95\% CI: 0.84, 1.54) times higher odds of developing ED.

\section{Discussion}

In our nationally representative study of older men, we found that the odds of developing ED were higher but did not reach nominal statistical significance for IQR increases in $\mathrm{PM}_{2.5}$ exposures, with the 4 year moving average exposure having the highest odds ratio (1.17, 95\% CI: 0.91 , 1.50). The observed associations between recent longterm average $\mathrm{PM}_{2.5}$ level and ED were not significantly modified by any of the examined risk factors for ED.

This study is the first to investigate the association between incident ED and exposure to ambient air pollution. Although not statistically significant, we found $\mathrm{PM}_{2.5}$ exposures to be consistently associated with higher odds of developing ED. Our findings were consistent across a broad range of sensitivity analyses. The relatively small study size may in part account for the imprecise estimates of association, as we had limited 
Table 1 Characteristics of NSHAP Male Participants Included in the Incident ED Study ${ }^{\text {a }}$

\begin{tabular}{|c|c|c|c|}
\hline Characteristic & Men with ED & Men without ED & $P$-value \\
\hline Number of Participants $^{c}$ & 132 & 280 & \\
\hline Age, mean (SD) & $70.73(6.27)$ & $69.55(6.06)$ & 0.07 \\
\hline \multicolumn{4}{|l|}{ Race, n (\%) } \\
\hline Non-Hispanic white & 104 (78.79\%) & $186(66.67 \%)$ & 0.01 \\
\hline Non-Hispanic black & $17(12.88 \%)$ & $39(13.98 \%)$ & \\
\hline Hispanic non-black & $8(6.06 \%)$ & $43(15.41 \%)$ & \\
\hline Other & $3(2.27 \%)$ & $11(3.94 \%)$ & \\
\hline \multicolumn{4}{|l|}{ Region } \\
\hline Northeast & $24(18.18)$ & $56(20.07)$ & 0.03 \\
\hline Southeast & 37 (28.03) & $54(19.35)$ & \\
\hline Midwest & $26(19.70)$ & $39(13.98)$ & \\
\hline Central & $18(13.64)$ & $47(16.85)$ & \\
\hline West & $27(20.45)$ & $83(29.75)$ & \\
\hline \multicolumn{4}{|l|}{ Education Level, n (\%) } \\
\hline Less than High School & $11(8.33 \%)$ & $60(21.43 \%)$ & 0.004 \\
\hline H.S. or vocational school & $74(56.06 \%)$ & 131 (46.79\%) & \\
\hline College degree or greater & 47 (35.61\%) & 89 (31.79\%) & \\
\hline $\begin{array}{l}\text { Median Household Income }{ }^{d} \text {, } \\
\text { mean (SD) }\end{array}$ & $58.97(24.54)$ & $61.09(31.01)$ & 0.49 \\
\hline Diabetes, n (\%) & $37(28.42 \%)$ & $44(15.71 \%)$ & 0.003 \\
\hline Hypertension ${ }^{\mathrm{e}}, \mathrm{n}(\%)$ & $53(40.46 \%)$ & $120(43.80 \%)$ & 0.52 \\
\hline Elevated CRP, (>1), n (\%) & $86(65.65 \%)$ & $161(57.91 \%)$ & 0.14 \\
\hline BMI $\left(\mathrm{kg} / \mathrm{m}^{2}\right)$, mean $(\mathrm{SD})$ & $30.16(5.66)$ & $29.09(5.37)$ & 0.07 \\
\hline Exercise (weekly or more), n (\%) & $91(68.94 \%)$ & $197(70.36 \%)$ & 0.77 \\
\hline Current smoker, n (\%) & $17(12.88 \%)$ & $46(16.43 \%)$ & 0.35 \\
\hline Elevated depression, $\mathrm{f}$ (\%) & $23(17.42 \%)$ & $39(13.93 \%)$ & 0.35 \\
\hline $\mathrm{PM}_{2.5}{ }^{\mathrm{g}}\left(\mu \mathrm{g} / \mathrm{m}^{3}\right)$, mean $(\mathrm{SD})$ & $8.87(2.12)$ & $8.63(2.30)$ & 0.32 \\
\hline
\end{tabular}

${ }^{a}$ Statistics are given for male participants from ED analysis, results are given as $\mathrm{n}(\%)$ or mean (SD)

${ }^{b} p$ values calculated for difference between groups using chi-square tests for categorical variables and $t$-test for difference in means

'Men with ED are defined as subjects replying yes to ED question (129) or reporting ED medication usage (10) in Wave 2 and not Wave 1 (7 men replied yes to both); Men without ED are subjects who replied no to ED question and ED medication use in both waves

dMedian household income is from census tract of each participant, results given in thousands of dollars

$e^{\text {e }}>90 \mathrm{mmHg}$ diastolic and/or $>140 \mathrm{mmHg}$ systolic averaged from 2 or 3 blood pressure measurements

${ }^{\mathrm{f}}$ Elevated depression defined as a score of 9 or greater on the CESD-11

${ }^{9} \mathrm{PM}_{2.5}=$ Particulate matter $\leq 2.5 \mu \mathrm{m}$ in diameter, 1 year moving average values estimated using concentration estimated at closest $6 \times 6 \mathrm{~km}$ grid point to participant residence using GIS-based spatio-temporal models

power to detect associations in the range of the observed estimates.

Support for the hypothesis that ambient air pollution may impact ED incidence is provided by epidemiologic studies of cardiovascular outcomes, which have consistently linked long-term $\mathrm{PM}_{2.5}$ exposure to vascular and endothelial dysfunction, biological pathways that have been linked to both ED and cardiovascular disease [27]. For example, a number of studies have found significant associations between ambient $\mathrm{PM}_{2.5}$ and various measures of cardiovascular disease, including increased blood pressure [28-30], stroke [31], brachial artery reactivity to shear stress [15, 32], and atherosclerosis [33-35]. Similarly, $\mathrm{PM}_{2.5}$ has also been shown to result in endothelial dysfunction [36] and oxidative stress [37] as assessed by measurements of the associated proteins Tumor Necrosis Factor-alpha (TNF- $\alpha$ ), intercellular adhesion molecules (iCAM), and vascular cell adhesion molecules (vCAM). In contrast to our findings, factors, such as BMI [38] and diabetes [15] have been shown to modify $\mathrm{PM}_{2.5}$ impacts on cardiovascular outcomes; however, our relatively small number of ED cases also likely limited our ability to detect the presence of any effect modification.

It is biologically plausible that exposure to $\mathrm{PM}_{2.5}$ can lead to ED. Exposure to $\mathrm{PM}_{2.5}$ is associated with oxidative stress and inflammation [36, 37], endothelial dysfunction [11], and atherosclerosis [33-35], potentially causing ED of vascular origin through both arteriogenic and veno-occlusive pathways [39]. Endothelial dysfunction and atherosclerosis, which are both strongly associated with $\mathrm{ED}$, lead to damage in the arteries, reducing blood flow to the penis [40]. Also, in erection biology, oxidative stress and endothelial dysfunction cause a reduction in endothelial nitric oxide (NO) production, leading to an increase in smooth muscle tone, impairment of vasodilation, and impairment of the ability to achieve an erection $[9,41]$. Additional support comes from animal models, where $\mathrm{PM}_{2.5}$ was shown to decrease NO bioavailability, which is required for penile erection [42].

Our findings that longer averages of 1 to 7 years are associated with ED are supported by studies that show higher risks for cardiovascular disease increases with longer $\mathrm{PM}_{2.5}$ exposure windows [43]. Implications of these findings are that adverse vascular effects of exposure to $\mathrm{PM}_{2.5}$ are cumulative over time, progressively leading to changes that manifest in a variety of vascular disorders, including ED. It is also interesting to note that we found lower, but still non-statistically significant associations between exposure to $\mathrm{PM}_{2.5}$ and prevalent cases of ED, possibly due to the fact that prevalent cases of ED may have been present for many years and are not related to the recent exposure windows used in this study.

Our study has some potential limitations that warrant discussion. First, the number of men with incident ED (132) was relatively small. The number of men with incident ED may have been underestimated in Wave 1 given that men were not asked about ED if they had no recent sexual activity, possibly due to being impotent. This 
Table 2 ORs (95\% Cls) for Incident ED per IQR Increase in $\mathrm{PM}_{2.5}{ }^{\mathrm{a}}$

\begin{tabular}{llllllll}
\hline & \multicolumn{1}{l}{$\mathrm{PM}_{2.5}$ Moving Average } \\
\cline { 2 - 7 } & 1 year & 2 year & 3 year & 4 year & 5 year & 6 year & 7 year \\
\hline Base Model $^{\mathrm{C}}$ & $1.08(0.84,1.40)$ & $1.07(0.84,1.36)$ & $1.08(0.85,1.35)$ & $1.09(0.87,1.36)$ & $1.08(0.88,1.34)$ & $1.08(0.88,1.34)$ & $1.08(0.88,1.32)$ \\
Adjusted Model $^{d}$ & $1.16(0.87,1.55)$ & $1.16(0.89,1.53)$ & $1.17(0.90,1.52)$ & $1.17(0.91,1.50)$ & $1.16(0.91,1.48)$ & $1.16(0.92,1.47)$ & $1.16(0.92,1.46)$
\end{tabular}

ancident ED is defined as either replying yes to ED question or reported ED medication usage in Wave 2 but not in Wave 1, multiple imputation using FCS algorithm run 100 times, results given are mean ORs (95\% Confidence Intervals)

${ }^{\mathrm{b}} \mathrm{PM}_{2.5} 1$ year IQR $=3.25 \mu \mathrm{g} / \mathrm{m}^{3}, 2$ years IQR $=3.12 \mu \mathrm{g} / \mathrm{m}^{3}, 3$ years IQR $=3.18 \mu \mathrm{g} / \mathrm{m}^{3}, 4$ years IQR $=3.12 \mu \mathrm{g} / \mathrm{m}^{3}, 5$ years IQR $=3.10 \mu \mathrm{g} / \mathrm{m}^{3}, 6 \mathrm{years} \mathrm{IQR}=3.15 \mu \mathrm{g} / \mathrm{m}^{3}$, 7 years IQR $=3.10 \mu \mathrm{g} / \mathrm{m}^{3}$

'Logistic regression models include adjustment for age and geographic region (West, Midwest, Central, South, Northeast) in base models

${ }^{\mathrm{d}}$ Additional adjustment for ethnic group, education (<H.S., H.S., College), current smoking status, obesity, depression, diabetes, season, and median household income in adjusted models

potential outcome misclassification, if any, is likely small, given that multiple imputation was performed to predict incident ED status for men without ED data (39.6\% in Wave 1 and $13.6 \%$ in Wave 2), with similar results to using non-imputed data. Importantly, selection bias was also unlikely, given that pollutant exposures and characteristics of men with and without ED information were similar across both data collection waves (Additional File 1: Table S1). Second, exposures were estimated using spatio-temporal models created from ambient monitor measurements that are imperfect measures of personal exposures to ambient air pollution. However, our exposure assessment method minimized exposure error resulting from spatial variation in $\mathrm{PM}_{2.5}$ concentrations, as the distance of the grid point estimates to residential addresses were minimal and substantially less than would otherwise occur if more traditional closest stationary ambient monitor concentrations were used to assess exposures. Any remaining exposure error would likely bias our odds ratios towards the null, as shown by previous studies that show that chronic health risks are underestimated using nearest monitor exposures [44-46]. Third, ED status was ascertained using self-reports of ED and medication use, which may result in outcome misclassification, likely biasing our results towards the null given its independence with pollutant exposures and given our binary outcome. The study would be improved by confirming ED status with clinical diagnosis. Fourth, the NSHAP study consisted of community dwelling older adults, limiting its generalizability to younger men and institutionalized men. Lastly, there are a number of confounding variables that could be included in future studies that were not available for all participants in this study, resulting in potential residual confounding. Examples include an improved measure of individual SES (beyond our use of education as an SES proxy), given its association with both higher pollutant levels [47] and ED [3], and more comprehensive information on medication usage and underlying health conditions related to ED.

Important strengths of this study include our NSHAP population, which is nationally representative of older adults. In this study, we analyzed the impacts of $\mathrm{PM}_{2.5}$ on incident ED controlling for key participant-specific demographic characteristics and accounting for medication use. This comprehensive characterization of each participant allowed us to control for potential confounders and to investigate the possibility of effect modification on a participant specific basis. The longitudinal nature of participant data also allowed us to capture newly developed cases of ED and analyze the impact of ambient air pollution on incident ED. Additionally, we assessed $\mathrm{PM}_{2.5}$ exposures for each participant using Geographic Information System (GIS) based spatiotemporal models, which reduced exposure error in our exposure estimates. Importantly, our findings were robust to our method of analysis, with results from several sensitivity analyses being qualitatively similar to those for our main analysis.

Table 4 ORs (95\% Cls) for Incident ED per IQR Increment of $\mathrm{O}_{3}$ and $\mathrm{NO}_{2}^{\mathrm{a}}$

\begin{tabular}{llllllll}
\hline & \multicolumn{6}{l}{ Moving Averages } & \\
& 1 year & 2 year & 3 year & 4 year & 5 year & 6 year & 7 year \\
\hline $\mathrm{O}_{3}^{\mathrm{b}}(n=375)$ & $1.27(0.89,1.82)$ & $1.29(0.93,1.79)$ & $1.19(0.86,1.64)$ & $1.20(0.88,1.65)$ & $1.17(0.87,1.57)$ & $1.24(0.92,1.68)$ & $1.24(0.92,1.66)$ \\
$\mathrm{NO}_{2}^{c}(n=265)$ & $1.10(0.70,1.71)$ & $1.01(0.64,1.58)$ & $1.07(0.70,1.63)$ & $1.11(0.70,1.76)$ & $1.10(0.71,1.72)$ & $1.12(0.71,1.76)$ & $1.02(0.66,1.59)$ \\
\hline
\end{tabular}

Incident ED is defined as either replying yes to ED question or reporting ED medication use in Wave 2 but not in Wave $1 ; 125$ men had incident ED with $\mathrm{O}_{3}$ data available and 84 men had incident $\mathrm{ED}$ with $\mathrm{NO}_{2}$ data available; results given are ORs ( $95 \%$ Confidence Intervals); Logistic regression models include adjustment for age, geographic region (West, Midwest, Central, South, Northeast), ethnic group, education (<H.S., H.S., College), current smoking status, obesity (BMI $\geq 30$ ), diabetes, depression, season, and median household income

${ }^{\mathrm{b}}$ Summer (April-Sept) only, 1 year IQR $=8.21 \mathrm{ppb}, 2$ years IQR $=7.17 \mathrm{ppb}, 3$ years IQR $=7.13 \mathrm{ppb}$, 4 years IQR $=7.16 \mathrm{ppb}, 5$ years IQR $=6.77 \mathrm{ppb}, 6$ years $\mathrm{IQR}=6.96 \mathrm{ppb}, 7$ years IQR $=6.81 \mathrm{ppb}$

${ }^{c} 1$ year IQR $=7.49 \mathrm{ppb}$, 2 years IQR $=7.35 \mathrm{ppb}, 3$ years IQR $=7.18 \mathrm{ppb}$, 4 years IQR $=7.82 \mathrm{ppb}, 5$ years IQR $=7.57 \mathrm{ppb}, 6$ years IQR $=7.80 \mathrm{ppb}$,

7 years IQR $=7.81 \mathrm{ppb}$ 
Table 3 Effect Modification of the 4 Year Moving Average $\mathrm{PM}_{2.5^{-} \text {-Incident ED Association }}{ }^{\mathrm{a}}$

\begin{tabular}{|c|c|}
\hline Effect Modifier & Odds Ratio $(95 \%$ C \\
\hline \multicolumn{2}{|l|}{ Obesity } \\
\hline $\mathrm{BMI}<30 \mathrm{~kg} / \mathrm{m}^{2}$ & $1.14(0.88,1.46)$ \\
\hline $\mathrm{BMI} \geq 30 \mathrm{~kg} / \mathrm{m}^{2}$ & $0.92(0.74,1.14)$ \\
\hline \multicolumn{2}{|l|}{ CRP } \\
\hline Low (<1 mg/L) & $1.19(0.92,1.52)$ \\
\hline Elevated ( $\geq 1 \mathrm{mg} / \mathrm{L}$ ) & $0.92(0.75,1.14)$ \\
\hline \multicolumn{2}{|l|}{ Diabetes } \\
\hline No & $1.13(0.86,1.48)$ \\
\hline Yes & $0.94(0.74,1.19)$ \\
\hline \multicolumn{2}{|l|}{ Hypertension } \\
\hline No & $1.16(0.91,1.48)$ \\
\hline Yes & $1.03(0.85,1.24)$ \\
\hline \multicolumn{2}{|l|}{ Depression } \\
\hline No & $1.13(0.84,1.52)$ \\
\hline Yes & $0.95(0.73,1.23)$ \\
\hline \multicolumn{2}{|l|}{ Exercise } \\
\hline None & $1.16(0.90,1.49)$ \\
\hline$\geq 1$ times/week & $1.03(0.83,1.27)$ \\
\hline \multicolumn{2}{|l|}{ Current smoker } \\
\hline No & $1.19(0.89,1.61)$ \\
\hline Yes & $1.04(0.80,1.35)$ \\
\hline
\end{tabular}

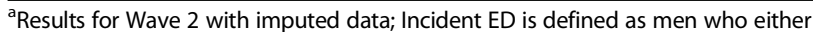
replied yes to ED question or reported ED medication usage in Wave 2; the comparison group of men without ED replied no to the ED question and ED medication use in both waves; logistic model includes adjustment for age, geographic region, ethnic group, education ( $<$ H.S., H.S., College), current smoking status, obesity, diabetes, depression, season, median household income; Reference group is $\mathrm{PM}_{2.5} 4$ year moving average exposures (IQR $=3.12 \mu \mathrm{g} / \mathrm{m}^{3}$ )

\section{Conclusions}

In summary, we found positive associations between recent long-term ambient $\mathrm{PM}_{2.5}$ levels and $\mathrm{ED}$ that did not reach nominal statistical significance. The associations were stronger for longer-term moving averages of exposure. Given that our study is the first to examine associations between ambient air pollution and ED, further research investigating the association of $\mathrm{PM}_{2.5}$ and incident ED should be conducted using larger sample sizes. If the relationship between $\mathrm{PM}_{2.5}$ and incident $\mathrm{ED}$ does in fact exist, limiting exposure to $\mathrm{PM}_{2.5}$ may decrease the number of incident cases of ED in older men, a common condition that affects an increasing number of men.

\section{Additional file}

Additional file 1: Erectile Dysfunction and Exposure to Ambient Air Pollution in a Nationally Representative Cohort of Older Men. Table S1. Wave-Specific Comparison of NSHAP Male Participants with and without Available ED Data. Table S2. ORs (95\% Cls) for Prevalent ED per IQR
Increase in $\mathrm{PM}_{25}$. Table S3. ORs (95\% Cls) for Incident ED per IQR Increase in PM2.5: Complete Case Analysis. (DOCX 35 kb)

\section{Abbreviations}

BMI: Body mass index; CESD: Center for epidemiological studies depression scale; CRP: C-reactive protein; ED: Erectile dysfunction; EPA: Environmental protection agency; GAMMs: Generalized additive mixed models;

GIS: Geographic information systems; iCAM: Intercellular adhesion molecules; IMPROVE: Interagency monitoring of protected visual environments; IQR: Interquartile range; $\mathrm{NO}$ : Nitric oxide; $\mathrm{NO}_{2}$ : Nitrogen dioxide; $\mathrm{O}_{3}$ : Ozone; OR: Odds ratio; $\mathrm{PM}_{2.5}$ : Particulate matter with aerodynamic diameters $\leq 2.5 \mu \mathrm{m}$; SES: Socioeconomic status; TNF-a: Tumor necrosis factor-alpha; vCAM: Vascular cell adhesion molecules

\section{Acknowledgements}

We thank Dr. Jeffrey Yanosky from the Pennsylvania State University for providing daily $\mathrm{PM}_{2.5}$ grid data.

\section{Funding}

This work was funded by NIEHS grant 1R01ES022657-01A1. Development of $\mathrm{PM}_{2.5}$ GIS-based spatio-temporal models was supported by National Institutes of Health grant \#1 R01 ES019168. NSHAP is supported by the National Institutes of Health, including the National Institute on Aging (R37AG030481; R01AG033903), the Office of Women's Health Research, the Office of AIDS Research, and the Office of Behavioral and Social Sciences Research (R01AG021487), and by NORC which was responsible for the data collection.

\section{Availability of data and materials}

The data that support the findings of this study are available on request from the corresponding author HS. The data are not publicly available due to containing individually identifiable information that could compromise research participant privacy.

\section{Authors' contributions}

$\mathrm{LT}$ analyzed and interpreted the participant and pollutant data and wrote the manuscript. JM advised on the data analysis and writing of the manuscript. VP prepared the pollutant data and advised on data analysis. MM, MK, and BC advised on the study design, data analysis, and manuscript. $\mathrm{HS}$ also advised on the study design and data analysis, provided critical revision of the manuscript for important intellectual content, and obtained funding support. All authors read and approved the final manuscript.

\section{Competing interests}

The authors declare that they have no competing interests.

\section{Consent for publication}

Not applicable.

\section{Ethics approval and consent to participate}

The protocol was approved by the Institutional Review Boards of Northeastern University, the University of Chicago and NORC at the University of Chicago. All respondents provided written informed consent.

\section{Author details}

${ }^{1}$ Department of Health Sciences, Northeastern University, 360 Huntington Avenue, Boston, MA 02115, USA. ${ }^{2}$ MCPHS University, 179 Longwood Avenue, Boston, MA 02115, USA. ${ }^{3}$ Department of Epidemiology, Harvard T.H. Chan School of Public Health, 677 Huntington Ave., Boston, MA 02115, USA. ${ }^{4}$ Department of Environmental Health Sciences, Columbia University Mailman School of Public Health, 722 W. 168th Street, \#1105C, New York, NY 10032, USA. ${ }^{5}$ Department of Biostatistics, Harvard T.H. Chan School of Public Health, 677 Huntington Ave., Boston, MA 02115, USA. 'Department of Civil and Environmental Engineering, Tufts University, 200 College Avenue, 301 Anderson Hall, Medford, MA 02155, USA. 
Received: 5 August 2016 Accepted: 8 February 2017 Published online: 17 February 2017

\section{References}

1. National Institutes of Health: NIH Consensus Conference. Impotence. NIH consensus development panel on impotence. JAMA. 1993;270(1):83-90.

2. Feldman HA, Goldstein I, Hatzichristou DG, Krane RJ, McKinlay JB. Impotence and its medical and psychosocial correlates: results of the Massachusetts male aging study. J Urol. 1994;151(1):54-61.

3. Johannes CB, Araujo AB, Feldman HA, Derby CA, Kleinman KP, McKINLAY JB. Incidence of erectile dysfunction in men 40 to 69 years old: longitudinal results from the Massachusetts male aging study. J Urol. 2000;163(2):460-3.

4. Aytac I, McKinlay J, Krane R. The likely worldwide increase in erectile dysfunction between 1995 and 2025 and some possible policy consequences. BJU Int. 1999:84:50-6.

5. Hockenberry MS, Masson P. Erectile dysfunction in the elderly. Curr Geriatr Rep. 2015:4(1):33-43.

6. De Boer B, Bots M, Nijeholt A, Verheij TJ. The prevalence of bother, acceptance, and need for help in men with erectile dysfunction. J Sex Med. 2005;2(3):445-50.

7. Solomon H, Man JW, Jackson G. Erectile dysfunction and the cardiovascular patient: endothelial dysfunction is the common denominator. Heart. 2003;89(3):251-3.

8. Inman BA, Sauver JL, Jacobson DJ, McGree ME, Nehra A, Lieber MM, Roger $V L$, Jacobsen SJ. A population-based, longitudinal study of erectile dysfunction and future coronary artery disease. Mayo Clinic Proceedings. 2009;84(2):108-113.

9. Albersen M, Orabi H, Lue TF. Evaluation and treatment of erectile dysfunction in the aging male: a mini-review. Gerontology. 2012;58(1):3-14.

10. Elesber AA, Solomon H, Lennon RJ, Mathew V, Prasad A, Pumper G, Nelson RE, McConnell JP, Lerman LO, Lerman A. Coronary endothelial dysfunction is associated with erectile dysfunction and elevated asymmetric dimethylarginine in patients with early atherosclerosis. Eur Heart J. 2006;27(7):824-31.

11. Brook RD, Franklin B, Cascio W, Hong Y, Howard G, Lipsett M, Luepker R, Mittleman M, Samet J, Smith Jr SC, Tager I. Expert panel on population and prevention science of the american heart association: Air pollution and cardiovascular disease: a statement for healthcare professionals from the expert panel on population and prevention science of the american heart association. Circulation. 2004;109(21):2655-71.

12. Brook RD, Rajagopalan S, 3rd Pope CA, Brook JR, Bhatnagar A, Diez-Roux AV, Holguin F, Hong Y, Luepker RV, Mittleman MA, Peters A, Siscovick D, Smith Jr SC, Whitsel L, Kaufman JD, American Heart Association Council on Epidemiology and Prevention, Council on the Kidney in Cardiovascular Disease, and Council on Nutrition, Physical Activity and Metabolism. Particulate matter air pollution and cardiovascular disease: an update to the scientific statement from the american heart association. Circulation. 2010;121(21):2331-78.

13. 3rd Pope CA, Burnett RT, Thurston GD, Thun MJ, Calle EE, Krewski D, Godleski JJ. Cardiovascular mortality and long-term exposure to particulate air pollution: epidemiological evidence of general pathophysiological pathways of disease. Circulation. 2004;109(1):71-7.

14. Donaldson K, Tran CL. Inflammation caused by particles and fibers. Inhal Toxicol. 2002;14(1):5-27.

15. O'Neill MS, Veves A, Zanobetti A, Sarnat JA, Gold DR, Economides PA, Horton ES, Schwartz J. Diabetes enhances vulnerability to particulate air pollution-associated impairment in vascular reactivity and endothelial function. Circulation. 2005;111(22):2913-20.

16. O'Muircheartaigh C, Eckman S, Smith S. Statistical design and estimation for the national social life, health, and aging project. J Gerontol Ser B Psychol Sci Soc Sci. 2009;64B suppl 1:112-9.

17. Keys A, Fidanza F, Karvonen MJ, Kimura N, Taylor HL. Indices of relative weight and obesity. J Chronic Dis. 1972;25(6):329-43.

18. Pickering TG, Hall JE, Appel LJ, Falkner BE, Graves J, Hill MN, Jones DW, Kurtz T, Sheps SG, Roccella EJ. Subcommittee of professional and public education of the american heart association council on high blood pressure research: recommendations for blood pressure measurement in humans and experimental animals: part 1: blood pressure measurement in humans: a statement for professionals from the subcommittee of professional and public education of the american heart association council on high blood pressure research. Hypertension. 2005;45(1):142-61.
19. Hansson L, Lindquist L. C-reactive protein: its role in the diagnosis and follow-up of infectious diseases. Curr Opin Infect Dis. 1997;10(3):196-201.

20. Kohout FJ, Berkman LF, Evans DA, Cornoni-Huntley J. Two shorter forms of the CES-D (Center for Epidemiological Studies Depression) depression symptoms index. J Aging Health. 1993;5(2):179-93.

21. Harada N, Takeshita J, Ahmed I, Chen R, Petrovitch H, Ross GW, Masaki K. Does cultural assimilation influence prevalence and presentation of depressive symptoms in older Japanese American men? the Honolulu-Asia aging study. Am J Geriatr Psychiatry. 2012;20(4):337-45.

22. Yanosky JD, Paciorek CJ, Laden F, Hart JE, Puett RC, Liao D, Suh HH. Spatiotemporal modeling of particulate air pollution in the conterminous United States using geographic and meteorological predictors. Environ Health. 2014;13(1):63.

23. Environmental Protection Agency (EPA). :http://www.epa.gov/ttn/airs/ airsaqs/.(2009) Accessed 27 Dec 2015

24. Interagency Monitoring of Protected Visual Environments (IMPROVE). :http:// vista.cira.colostate.edu/improve/.(2013) Accessed 27 Dec 2015

25. Lee KJ, Carlin JB. Multiple imputation for missing data: fully conditional specification versus multivariate normal imputation. Am J Epidemiol. 2010; 171(5):624-32

26. Keene LC, Davies PH. Drug-related erectile dysfunction. Adverse Drug React Toxicol Rev. 1999;18(1):5-24.

27. Bivalacqua TJ, Usta MF, Champion HC, Kadowitz PJ, Hellstrom WJ. Endothelial dysfunction in erectile dysfunction: role of the endothelium in erectile physiology and disease. J Androl. 2003;24(S6):S17-37.

28. Ibald-Mulli A, Stieber J, Wichmann HE, Koenig W, Peters A. Effects of air pollution on blood pressure: a population-based approach. Am J Public Health. 2001;91(4):571-7.

29. Zanobetti A, Canner MJ, Stone PH, Schwartz J, Sher D, Eagan-Bengston E, Gates KA, Hartley LH, Suh H, Gold DR. Ambient pollution and blood pressure in cardiac rehabilitation patients. Circulation. 2004;110(15):2184-9.

30. Diez Roux AV, Auchincloss AH, Dvonch JT, Brown PL, Barr RG, Daviglus ML, Goff Jr DC, Kaufman JD, O'Neill MS. Associations between recent exposure to ambient fine particulate matter and blood pressure in the Multi-Ethnic Study of Atherosclerosis. Environmental Health Perspectives. 2008;116(4): 486-91.

31. Wellenius GA, Schwartz J, Mittleman MA. Air pollution and hospital admissions for ischemic and hemorrhagic stroke among medicare beneficiaries. Stroke. 2005;36(12):2549-53.

32. Schneider A, Neas L, Herbst MC, Case M, Williams RW, Cascio W, Hinderliter A, Holguin F, Buse JB, Dungan K. Endothelial dysfunction: associations with exposure to ambient fine particles in diabetic individuals. Environ Health Perspect. 2008;1 16(12):1666-74.

33. Künzli N, Jerrett M, Garcia-Esteban R, Basagaña X, Beckermann B, Gilliland F, Medina M, Peters J, Hodis HN, Mack WJ. Ambient air pollution and the progression of atherosclerosis in adults. PLoS One. 2010;5(2):e9096.

34. Diez Roux AV, Auchincloss AH, Franklin TG, Raghunathan T, Barr RG, Kaufman J, Astor B, Keeler J. Long-term exposure to ambient particulate matter and prevalence of subclinical atherosclerosis in the multi-ethnic study of atherosclerosis. Am J Epidemiol. 2008;167(6):667-75.

35. Kaufman JD, Adar SD, Barr RG, Budoff M, Burke GL, Curl CL, Daviglus ML, Roux AVD, Gassett AJ, Jacobs DR: Association between air pollution and coronary artery calcification within six metropolitan areas in the USA (the Multi-Ethnic Study of Atherosclerosis and Air Pollution): a longitudinal cohort study. The Lancet. 2016;388(10045):696-704.

36. Brook RD, Brook JR, Urch B, Vincent R, Rajagopalan S, Silverman F. Inhalation of fine particulate air pollution and ozone causes acute arterial vasoconstriction in healthy adults. Circulation. 2002;105(13):1534-6.

37. Bind MA, Baccarelli A, Zanobetti A, Tarantini L, Suh H, Vokonas P, Schwartz J. Air pollution and markers of coagulation, inflammation, and endothelial function: associations and epigene-environment interactions in an elderly cohort. Epidemiology. 2012;23(2):332-40.

38. Zeka A, Sullivan JR, Vokonas PS, Sparrow D, Schwartz J. Inflammatory markers and particulate air pollution: characterizing the pathway to disease. Int J Epidemiol. 2006;35(5):1347-54.

39. Gillon G, Barnea O. Erection mechanism of the penis: a model based analysis. J Urol. 2002;168(6):2711-5.

40. Kloner RA, Speakman M. Erectile dysfunction and atherosclerosis. Curr Atheroscler Rep. 2002;4(5):397-401.

41. Vanhoutte P. Ageing and endothelial dysfunction. Eur Heart J-Suppl. 2002;4: A8. 
42. Nurkiewicz TR, Porter DW, Hubbs AF, Stone S, Chen BT, Frazer DG, Boegehold MA, Castranova V. Pulmonary nanoparticle exposure disrupts systemic microvascular nitric oxide signaling. Toxicol Sci. 2009:110(1):191-203.

43. Pope III CA, Dockery DW. Health effects of fine particulate air pollution: lines that connect. J Air Waste Manage Assoc. 2006;56(6):709-42.

44. Suh $\mathrm{HH}$, Zanobetti A. Exposure error masks the relationship between trafficrelated air pollution and heart rate variability. J Occup Environ Med. 2010;52(7):685-92.

45. Kioumourtzoglou M, Spiegelman D, Szpiro AA, Sheppard L, Kaufman JD, Yanosky JD, Williams R, Laden F, Hong B, Suh H. Exposure measurement error in PM2. 5 health effects studies: A pooled analysis of eight personal exposure validation studies. Environ Health. 2014;13(1):2.

46. Paciorek CJ, Yanosky JD, Puett RC, Laden F, Suh HH. Practical large-scale spatio-temporal modeling of particulate matter concentrations. The Annals of Applied Statistics. 2009;3(1):370-97.

47. Hajat A, Diez-Roux AV, Adar SD, Auchincloss AH, Lovasi GS, O'Neill MS, Sheppard L, Kaufman JD. Air pollution and individual and neighborhood socioeconomic status: evidence from the Multi-Ethnic Study of Atherosclerosis (MESA). Environ Health Perspect (Online). 2013;121(11-12): 1325

\section{Submit your next manuscript to BioMed Central} and we will help you at every step:

- We accept pre-submission inquiries

- Our selector tool helps you to find the most relevant journal

- We provide round the clock customer support

- Convenient online submission

- Thorough peer review

- Inclusion in PubMed and all major indexing services

- Maximum visibility for your research

Submit your manuscript at www.biomedcentral.com/submit 